\title{
The Role of Microbial Biofilms Consisting on the Contact Lenses in Ocular Infection, Taif, KSA
}

\author{
Sherifa Mostafa M. Sabra \\ *Microbiology Br., Biology Dept., Science Collage,Taif University, KSA Country :SA
}

\begin{abstract}
This study was carried out during 2013, from ophthalmic private clinics, Taif, KSA. All patients understudy were complained from using contact lenses (CLs). Incidence of ocular inflammation due to duration of CLs use, that showed the predominate of ocular inflammation were at $1^{\text {st }}, 2^{\text {nd }}, 3^{\text {rd }}, 4^{\text {th }}$, and $5^{\text {th }}$ days as 37.3 , $26.7,18,10.7$ and $7.3 \%$ respectively. Incidence of contact lenses type and inflammation affection, that showed the predominate of cosmetics CLs type were $65.3 \%$, then medical type as $34.7 \%$. The predominate inflammation were in bilateral eyes as $57.3 \%$, then unilateral eye as $42.7 \%$ respectively. Incidence of local ocular inflammation signs, that showed the predominate signs of ocular inflammation were redness, lacrimation, itching, F.B. sensation, secretion and edema were 72, 68, 56, 48, 36, and 24\% respectively. Incidence of CLs biofilm positive for microbial isolates, total CLs were examined 150, which resulted in $64 \%$ positive and $36 \%$ negative for microbial isolates respectively. Incidence of CLs biofilm microbial isolates types and species, total CLs were examined 96. The bacteria, fungus and protozoa were resulted in 70.8, 20.9, and 8.3\% respectively. The predominant isolates were Pseudomonas aeruginosa, Serratia marcescens, Staph. aureus, Fusarium spp., Staph. epidermidis, Candida albicans, Acanthamoeba keratitis and Strept. spp., as percentage 22.9, 16.7, 14.6, $11.5,10.4,9.4,8.3$ and $6.2 \%$ respectively.
\end{abstract}

Keywords: Ophthalmic clinic, Contact lenses, CLs, Ocular inflammation,Pseudomonas aeruginosa, Serratia marcescens, Staph. aureus, Fusarium spp., Staph. epidermidis, Candida albicans, Acanthamoeba keratitis, Strept. spp.,

\section{Introduction}

Biofilm is an aggregate of microorganisms in which cells adhere to each other on a surface. The microbial cells growing in a biofilm are physiologically distinct from planktonic cells of the same organism [14]. Biofilms are usually found on solid substrates submerged in or exposed to an aqueous solution. Given sufficient resources for growth, will quickly grow to be macroscopic. It contain many different types of microorganism, e.g. bacteria, archaea, protozoa, fungi and algae [5]. Biofilms have been found to be involved in a wide variety of microbial infections in the body, estimate $80 \%$ of all infections. Infectious processes in which biofilms have been implicated include common problems such as coating CLs [6].CLs cases are recognized as a potential source of pathogens associated with corneal ulcers, isolated from CLs associated corneal ulcers have often been shown to bethe same as found in the patient's CL case, thus providing evidence contaminated may be a replenish able source of pathogenic microbes.Bacterial, and fungal contamination of CL cases, daily wear cosmetic CL wearersfrom one practice were studied to determine the occurrence of fungal, bacterial, and Protozoal contamination. Found that $24 \%$ of CLs were colonized by Cladosporium spp. $41.7 \%$ and $10 \%$ from total, Candidaspp.37.5\% and $9 \%$ from total. Other fungi were isolated: Fusarium solani, Aspergillus versicolor, Exophiala, and Phoma [7].Bacterial biofilm formation on CLs, and cases may be a risk factor for CLassociated corneal infection and may explain the persistence of organisms in CL storage cases. Evaluated biofilm formation on, and microbial contamination of, CLs and CL storage cases from patients with microbial keratitis. CLs andCL storage cases from 20 wearers with microbial keratitis were sampled microbiologicallyand visualized using scanning electron microscopy (SEM). Culture results from thecornea were also noted. Bacterial biofilm was case $85 \%$ compared with CL surfaces 55\% and biofilm densitywas significantly greater on case surfaces. Microbial keratitis in CL wearers is frequently associated with bacterial biofilm in the CLstorage case. CL storage caseis a favorable environment for proliferation of certain organisms. Biofilm on CLs mayprolong the retention time of organisms at the ocular surface and increase their potentialpathogenicity [8].Complications due to CL wear affect roughly 5\% of CL wearers each year. Most complications arise when lenses are worn differently than prescribed. Sleeping in CLs is a common cause of complications. Many people go too long before replacing their CLs, wearing designed for 1, 14, or 30 days of wear for multiple months or years [9]. Direct microbial corneal infection is one of the most serious known complications of CL wear. Pseudomonas spp.and Staph. spp. are the isolated from corneal infections during cosmetic CL, followed by Acanthamoeba Spp., and rarely, fungi [10]. CLs wear is a major predisposing factor to infectious corneal ulcers [11].Pseudomonas aeruginosa invade the eye and causes ocular infection. Corneal hypoxia exacerbated Pseudomonas binding to the corneal epithelium, internalization of the microbes, and 
induction of the inflammatory response [12]. Bacterial associated with CL wear, are Staph. aureus, Staph. epidermidis and Strept. spp. [13]. A silver-impregnated lens case has been developed which helps to eradicate any potentially contaminating microbes that come in contact with the CL case [14]. Contamination of CLs is less frequent and associated with fewer organisms than CL cases, but correlates more closely with organisms that cause corneal infections [15]. Pseudomonas ocular infections are the most predominant. Compliance is a major issue surrounding the use of CLs because patient noncompliance often leads to contamination of the CL, storage case, or both [16].Pseudomonas aeruginosa and Staph. epidermis adhere much more strongly to silicone hydrogel CLs than conventional hydrogel contact lenses and that adhesion of Pseudomonas aeruginosa was 20 times stronger than adhesion of Staph.epidermidis [17].Microbes can reside on CLs and within CL cases, often in association as reservoirs for the establishment of eye infections [18].Fungal keratitis is caused by Fusarium spp., and less commonly by Candida spp.Clinical isolates were Fusarium and Candida albicans formed biofilms on all types of CLs tested [19].Ocular infection caused by bacteria species, fungi, and Acanthamoeba [20]. From of CL storage cases $24-81 \%$ are contaminated with microbial biofilms, with the frequency of contamination increasing in wearers suffering from microbial keratitis [21]. Eye infections are initiated when lens-ocular surface interactions modify and/or compromise the epithelial surface, allowing contaminating microbes to adhere and invade [22].Pseudomonas aeruginosawas the most CL, followed by Serratia marcescens, Staph. aureus, Acanthamoeba spp., and Fusarium spp. [23].CLs wear, is the most common risk factor for microbial keratitis and has steadily increased over the past decades In the etiology of CLsassociated microbial keratitis Pseudomonas spp. [24].CLs handling greatly increases the incidence of contamination, and the ocular surface has a tremendous ability to destroy organisms. However, even when removed aseptically from the eye, more than half of CLs are found to harbor microorganisms, almost exclusively bacteria. Coagulase-negative Staph. are most commonly cultured from worn CLs, however, approximately $10 \%$ harbor Gram negative and highly pathogenic species, even in asymptomatic subjects. In storage CL cases, the incidence of positive microbial bio burden is also typically greater than $50 \%$. All types of care solutions can become contaminated, including up to $30 \%$ of preserved products [25].Eye care practitioners (ECPs) would tend to agree that wearing CLs increases the risk for infection, but millions of patients are still fitted with CLs every year because ECPs feel that the risk is manageable and that their patients' eye health can be protected. Fusarium and Acanthamoeba keratitis outbreaks were a wake-up call to manufacturers, ECPs, and regulatory agencies that risk cannot be managed without diligence, and that the complex relationship between CL materials, solutions, and compliance needs to be better understood in order to optimize the efficacy of CL care and improve care guidelines [26].Eye has proven to be naturally adept at protecting itself from pathogenic intruders, but CL wear and cleaning products can adversely impact this innate ability. Keeping up to date on the latest information is challenging, and becomes more complex when trying to incorporate the new scientific data into clinical practice. Several factors prevent drawing a straight line from study findings to real-world results, such as patient compliance and potentially flawed diagnostic tools. Reviewed the latest research findings and opinions related to CL care and further explore compliance and its effect on ocular health [27].

The Aim:Microbial biofilmsare forming always with delayed usedor contaminated CLs. This will lead to building up the microbial source of ocular infection. This work was as a trial to prove the presence of dangerous infectious point within CLs biofilm. This study will be follow up some elected patients through presence of CLs use, ophthalmic complains and signs while confirmed by microbial scan of CLs for detection of the main microbial forming biofilms and causes of ocular infection.

\section{Materials and Methods}

Field study:This search was doing during 2013, the area of study was at Taif, KSA. All patients understudy were complained from using CLs.Itwascollected from Ophthalmic private clinics.Ethical approval consents were obtained from understudy patients, ophthalmologists, and private clinicsowners. That made a written form for using the medical data in this research without any appearance of personal data. Also all research working procedures were explained before participating.

\section{Ophthalmic clinical examination}

Data for all understudy patients were collected from ophthalmic clinics through patients complain, medical files and ophthalmologistsclinical examinations. The data were included duration of CLs use days for (1-5 days), CLs types (medical and cosmetics), inflammation site (unilateral and bilateral), and ocular inflammation signs (redness, itching, secretion, lacrimation, edema and forging body sensation).

\section{Specimens preparation}

Control specimenswereNo.=10from patients using CLswithout any ocular problem, and understudy specimens wereNo. $=150$ from patients complained of ocular infection problem resulted from CLs usage. 


\section{Microbial Scan}

CLs understudy were collected from each patients for microbial examination. Each CL was removed aseptically with sterilized plastic forceps with soft plastic covered tips and placed immediately in a labeled Bijou bottle containing $2 \mathrm{ml}$ sterile phosphate buffered saline (PBS). Bijou bottle was capped and vortexed vigorously for 5minutes to loosen any biofilm adhering to the lens surface. CLs extract remaining in Bijou bottle were used for microbiological culture, andwere transferred to microbiological laboratory for isolation within 30 minutes of collection.A sterile dilution was prepared from each extract, $10 \mu 1$ were inoculated on each of; $5 \%$ horse blood agar (BA), chocolate agar (CHO) and Neomycin blood agar (NEO), and sabouraud dextrose agar (SDA), (Oxoid Ltd.). Bacterial cultures growth were showing and recordedcolony number, types and morphology.Positive cultures were isolated, Gram stained and identified were using standard biochemical tests for microbiological identification (Micro-Scan, Abbott Ltd.).Fungal growths were identified by growth characteristics, colors of colony back, aerial spores and structural differences using lacto phenol cotton blue [2829].

\section{Protozoal Isolation And Identification}

Each CL extract was placed on a nutrient agar saline plate seeded with a Gram-negative bacteria such as E. coli. If Acanthamoeba are present, they will reproduce readily and become visible on the plate under 1020X objective on an inverted microscope [30].

Data Analysis: The data which were recorded during the study period were entered into Microsoft excel sheet [31].

VII. Results and Discussion

Table and figure 1: Incidence of ocular inflammation due to duration of CLs use

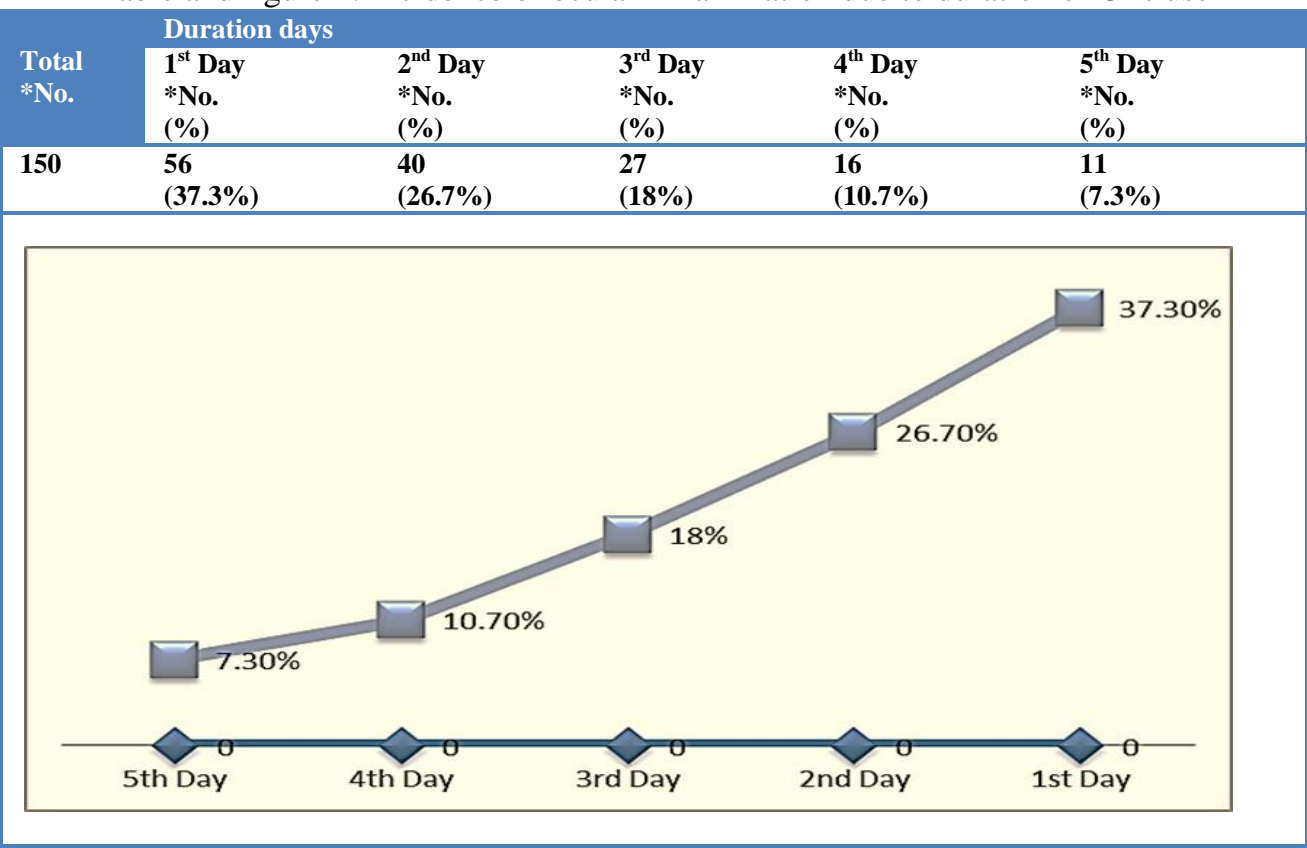

*No.: Number

Infectious processes in which biofilms have been implicated include common problems such as coating CLs [6]. Table and figure 1 reveal incidence of ocular inflammation due to duration of CLs use, that showed the predominate of ocular inflammation were at $1^{\text {st }}, 2^{\text {nd }}, 3^{\text {rd }}, 4^{\text {th }}$, and $5^{\text {th }}$ days as $37.3,26.7,18,10.7$ and $7.3 \%$ respectively. Isolated from CLs associated corneal ulcers have often been shown to be the same as found in the patient's CL case, thus providing evidence contaminated may be a replenish able source of pathogenic microbes [7].Complications due to CL wear affect roughly 5\% of CL wearers each year. Most complications arise when CLs are worn differently than prescribed. Sleeping in CLs is a common cause of complications. Many people go too long before replacing their CLs, wearing designed for 1, 14, or 30 days of wear for multiple months or years [9].Direct microbial corneal infection is one of the most serious known complications of CL wear [10].Microbes can reside on CLs and within CL cases, often in association as reservoirs for the establishment of eye infections [18].From of CL storage cases $24-81 \%$ are contaminated with microbial biofilms, with the frequency of contamination increasing in wearers suffering from microbial keratitis [21].Eye care practitioners (ECPs) would 
tend to agree that wearing CLs increases the risk for infection, but millions of patients are still fitted with CLs every year because ECPs feel that the risk is manageable and that their patients' eye health can be protected [26].

Table and figure 2: Incidence of CLs type and inflammation affection

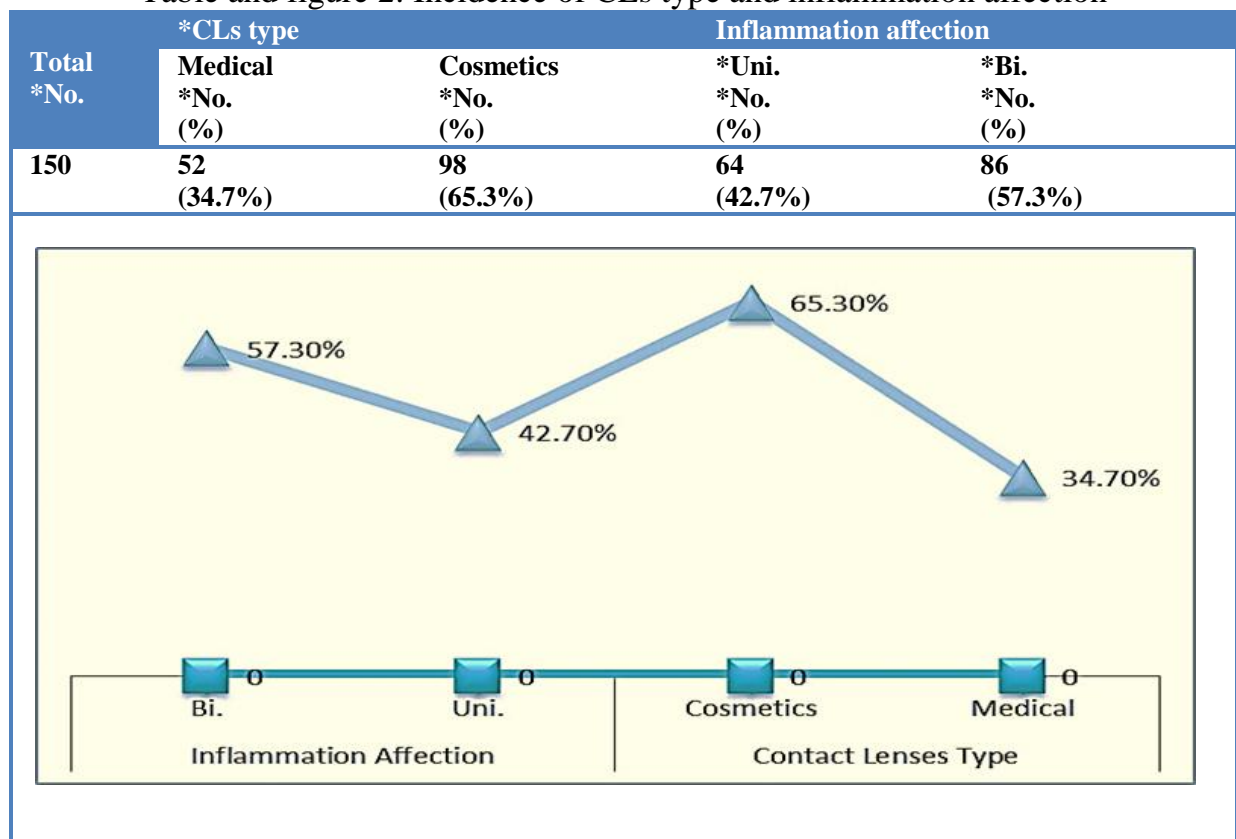

*No.; Number, ${ }^{*}$ CLs: contact lenses, ${ }^{*}$ Uni.: Unilateral, *Bi.: Bilateral

Table and figure 2 reveal incidence of contact lenses type and inflammation affection, that showed the predominate of cosmetics CLs type were $65.3 \%$, then medical type as $34.7 \%$. The predominate inflammation were in bilateral eyes as $57.3 \%$, then unilateral eye as $42.7 \%$ respectively. Microbe invade the eye and causes ocular infection. Corneal hypoxia exacerbated binding to the corneal epithelium, internalization of the microbes, and induction of the inflammatory response [12]. Compliance is a major issue surrounding the use of CLs because patient noncompliance often leads to contamination of the CL, storage case, or both [16].

Table and figure 3: Incidence of local ocular inflammation signs

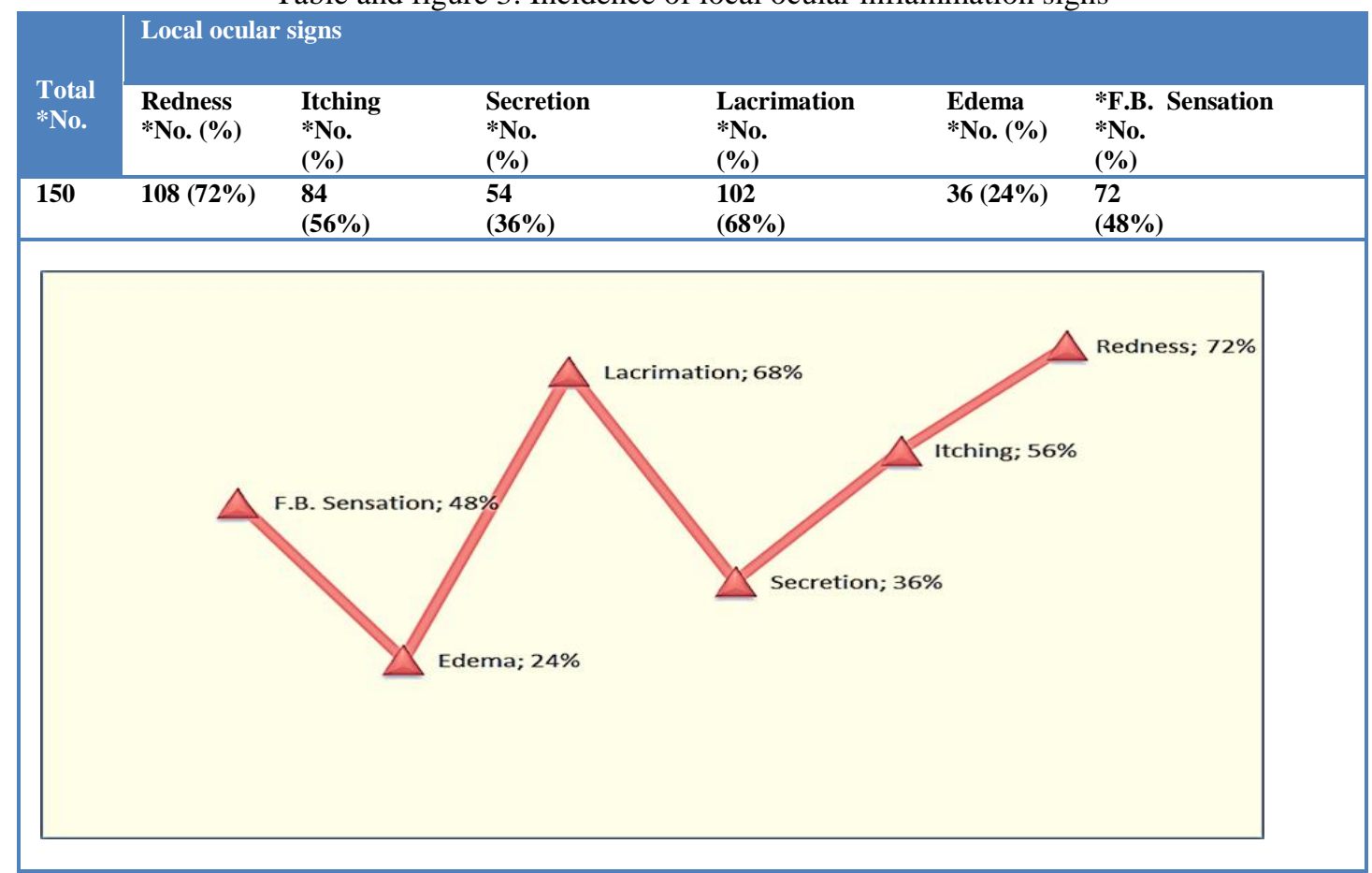

*NO.: Number, *F.B.: Forging Body 
Table and figure 3 reveal incidence of local ocular inflammation signs, that showed the predominate signs of ocular inflammation were redness, lacrimation, itching, F.B. sensation, secretion and edema were 72, 68, 56, 48,36 , and $24 \%$ respectively.CLs wear, is the most common risk factor for microbial keratitis and has steadily increased over the past decades In the etiology of CLs associated microbial keratitis [24].

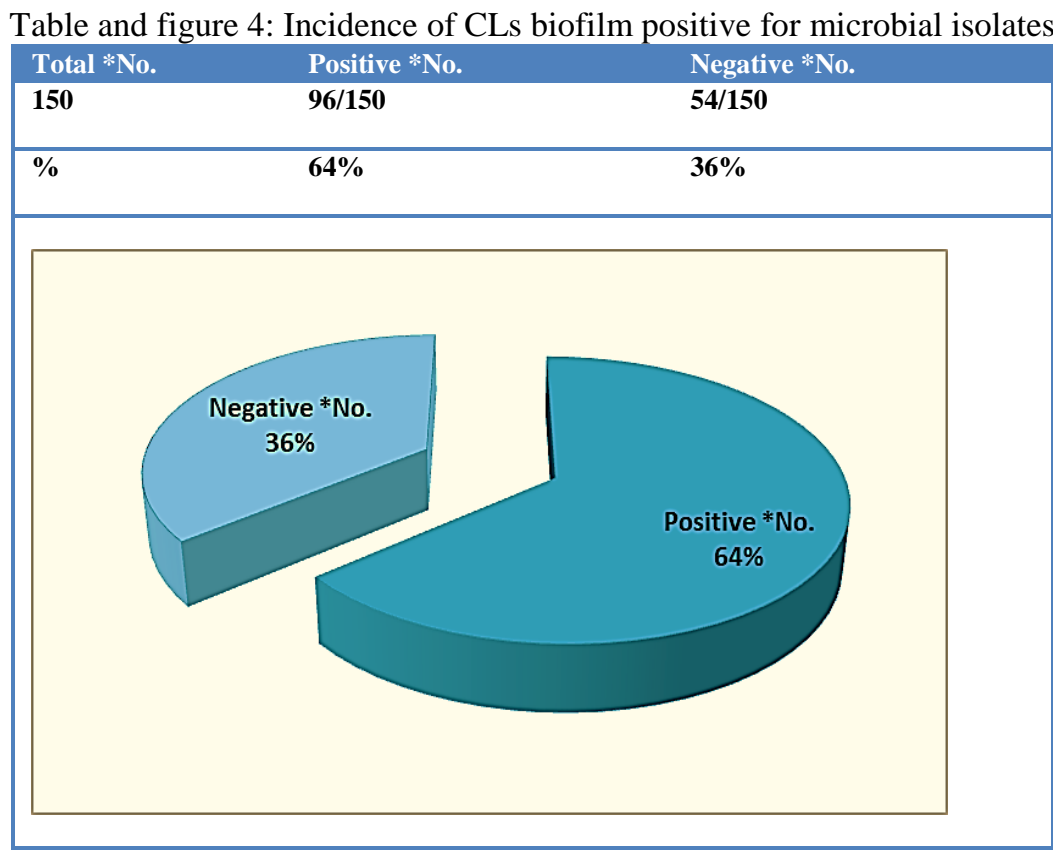

*No.: Number

Table and figure 4 reveal incidence of CLs biofilm positive for microbial isolates, total CLs were examined 150, which resulted in $64 \%$ positive and $36 \%$ negative for microbial isolates respectively.Bacterial, and fungal contamination of CL cases, daily wear cosmetic CL wearers from one practice were studied to determine the occurrence of fungal, bacterial, and Protozoal contamination [7].Bacterial biofilm was case $85 \%$ compared with CL surfaces $55 \%$ and biofilm density was significantly greater on case surfaces. Microbial keratitis in CL wearers is frequently associated with bacterial biofilm in the CL storage case [9].Contamination of CLs is less frequent and associated with fewer organisms than CL cases, but correlates more closely with organisms that cause corneal infections [15].From of CL storage cases $24-81 \%$ are contaminated with microbial biofilms, with the frequency of contamination increasing in wearers suffering from microbial keratitis [21]. Eye infections are initiated when lens-ocular surface interactions modify and/or compromise the epithelial surface, allowing contaminating microbes to adhere and invade [22].

Table and figure 5: Incidence of CL biofilm microbial isolates types and species

\begin{tabular}{|c|c|c|c|}
\hline Total & Positive & & Total \\
\hline$*$ No. $=96$ & *No. & $\%$ & $\%$ \\
\hline \multicolumn{4}{|l|}{ Bacteria: } \\
\hline \multicolumn{4}{|l|}{ Gram positive: } \\
\hline *Staph. aureus & $14 / 96$ & $14.6 \%$ & \\
\hline * Staph. epidermidis & $10 / 96$ & $10.4 \%$ & \\
\hline *Strept. *spp. & $6 / 96$ & $6.2 \%$ & \\
\hline \multicolumn{4}{|l|}{ Gram negative: } \\
\hline . Pseudomonas aeruginosa & $22 / 96$ & $22.9 \%$ & \\
\hline \multirow[t]{2}{*}{ Serratia marcescens } & $16 / 96$ & $16.7 \%$ & \\
\hline & & & $\begin{array}{l}68 / 96 \\
70.8 \% \\
\end{array}$ \\
\hline \multicolumn{4}{|l|}{ Fungus: } \\
\hline Candida albicans & 9/96 & $9.4 \%$ & \\
\hline \multirow[t]{2}{*}{ Fusarium *spp. } & $11 / 96$ & $11.5 \%$ & \\
\hline & & & $\begin{array}{l}20 / 96 \\
20.9 \% \\
\end{array}$ \\
\hline \multicolumn{4}{|l|}{ Protozoa: } \\
\hline \multirow[t]{2}{*}{ Acanthamoeba keratitis } & $8 / 96$ & $8.3 \%$ & \\
\hline & & & $\begin{array}{l}8 / 96 \\
8.3 \% \\
\end{array}$ \\
\hline
\end{tabular}




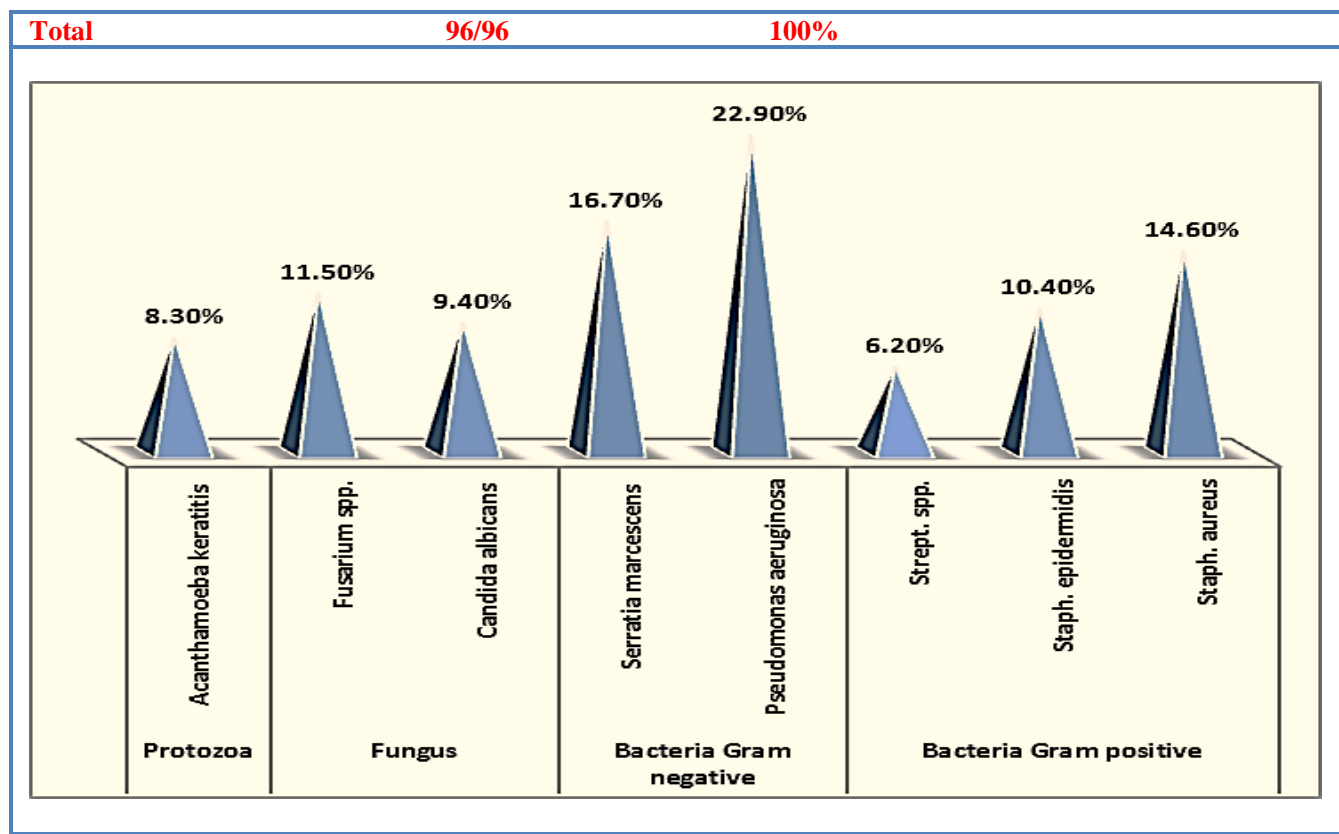

*No.; Number, *Staph.: Staphylococcus, *Strept.: Streptococcus, *spp.: Species

Table and figure 5 reveal incidence of CL biofilm microbial isolates types and species, total CLs were examined 96. The bacteria, fungus and protozoa were resulted in 70.8, 20.9, and 8.3\% respectively. The predominant isolates were Pseudomonas aeruginosa, Serratia marcescens, Staph. aureus, Fusarium spp., Staph. epidermidis, Candida albicans, Acanthamoeba keratitis and Strept. spp., as percentage 22.9, 16.7, 14.6, 11.5, 10.4, 9.4, 8.3 and $6.2 \%$ respectively.Found that $24 \%$ of CLs were colonized by Cladosporium spp. $41.7 \%$ and $10 \%$ from total, Candida spp. $37.5 \%$ and $9 \%$ from total. Other fungi were isolated: Fusarium solani, Aspergillus versicolor, Exophiala, and Phoma [7].Pseudomonas spp. and Staph. spp. are the isolated from corneal infections during cosmetic CL, followed by Acanthamoeba Spp., and rarely, fungi [10]. Pseudomonas aeruginosa invade the eye and causes ocular infection. [12]. Bacterial associated with CL wear, are Staph. aureus, Staph. epidermidis and Strept. spp. [13].Pseudomonas ocular infections are the most predominant [16] .Pseudomonas aeruginosa and Staph. epidermis adhere much more strongly to silicone hydrogel CLs than conventional hydrogel contact lenses and that adhesion of Pseudomonas aeruginosa was 20 times stronger than adhesion of Staph.epidermidis [17].Fungal keratitis is caused by Fusarium spp., and less commonly by Candida spp. were formed biofilms on all types of CLs tested [19].Pseudomonas aeruginosa was the most CL, followed by Serratia marcescens, Staph. aureus, Acanthamoeba spp., and Fusarium spp. [23]. CLs wear, is the most common risk factor for microbial keratitis associated microbial keratitis Pseudomonas spp. [24].Coagulase-negative Staph. are most commonly cultured from worn CLs, however, approximately $10 \%$ harbor Gram negative and highly pathogenic spp., even in asymptomatic subjects. In storage CL cases, the incidence of positive microbial bio burden is also typically greater than 50\%. All types of care solutions can become contaminated, including up to $30 \%$ of preserved products [25].Eye care practitioners (ECPs) would tend to agree that wearing CLs increases the risk for infection, but millions of patients are still fitted with CLs every year because ECPs feel that the risk is manageable and that their patients' eye health can be protected. Fusarium and Acanthamoeba keratitis outbreaks were a wake-up call to manufacturers, ECPs, and regulatory agencies that risk cannot be managed without diligence, and that the complex relationship between CL materials, solutions, and compliance needs to be better understood in order to optimize the efficacy of CL care and improve care guidelines [26]. Eye has proven to be naturally adept at protecting itself from pathogenic intruders, but CL wear and cleaning products can adversely impact this innate ability. Keeping up to date on the latest information is challenging, and becomes more complex when trying to incorporate the new scientific data into clinical practice. Several factors prevent drawing a straight line from study findings to real-world results, such as patient compliance and potentially flawed diagnostic tools. Reviewed the latest research findings and opinions related to CL care and further explore compliance and its effect on ocular health [27].

\section{Conclusions}

Clearly, the risk of infection while wearing CLs is low but a substantial increase in risk occurs when the CLs are used on an extended wear basis. Clinicians who prescribe CLs, patients who wear them and the industry that produces them have a vested interest in research enhancing the safety and efficacy of CLs. Certainly, minimizing complications that may lead to particularly microbial infection, is a priority. The process of CLrelated microbial keratitis and inflammation is thought to be preceded by the presence or transfer or both 
of microorganisms from the lens to the ocular surface.It is important in the understanding of factors associated with infectious and inflammatory complications. Promising mechanisms to prevent bacterial colonization on CLs and CLs cases are forthcoming, which may decrease the incidence of microbial driven CL complications.

\section{Acknowledgments}

Sending our thanks to all of; clinical medical staff and their owners of the private ophthalmic clinic at Taif, also for laboratory staff to enhancing this work.

\section{References}

[1]. Hall-Stoodley, L., Costerton, J. and Stoodley, P., 2004. Bacterial biofilms: from the natural environment to infectious diseases. Nature Reviews. Microbiology., 2: 95-108.

[2]. Lear, G. and Lewis, G., 2012. Microbial Biofilms: Current Research and Applications. Caister Academic Press.

[3]. An, D. and Parsek, M., 2007. The promise and peril of transcriptional profiling in biofilm communities. Current Opinion in Microbiology, 10: 292-296.

[4]. Karatan, E. and Watnick, P., 2009. Signals, regulatory networks, and materials that build and break bacterial biofilms. Microbiology and Molecular Biology Reviews, 73: 310-347.

[5]. Nadell, C., Xavier, J. and Foster, K., 2009. The sociobiology of biofilms. FEMS Microbiology Reviews, 33: $206-224$.

[6]. Imamura, Y., Chandra, J. and Mukherjee, P., 2008. Fusarium and Candida albicans biofilms on soft contact lenses: model development, influence of lens type, and susceptibility to lens care solutions". Antimicrobial Agents and Chemotherapy, 52: 171182.

[7]. Gray, T., Ray, T., Jane, F., and Sherwan, P., 1995. Acanthamoeba, bacterial, and fungal contamination of contact lens storage cases. British J. Ophthalmology, 79: 601-605.

[8]. McLaughlin-Borlace, L., Stapleton1, F. and Matheson, M. and Dart, J., 2002. Bacterial biofilm on contact lenses and lens storage cases in wearers with microbial keratitis. J. Applied Micro., 84: 827-838.

[9]. Liu, Z. and Pflugfelder, S., 2000. The effects of long-term contact lens wear on corneal thickness, curvature, and surface regularity. Ophthalmology., 107: 105-111.

[10]. Michael, J. and Barry, A., 2002. Contact lens associated corneal infections. Cline. Exp. Optometry, 85:141-148.

[11]. Bourcier, T., Thomas, F., Borderie, V., Chaumeil, C. and Laroche, L., 2003. Bacterial keratitis: predisposing factors, clinical and microbiological review of 300 cases. Br. J. Ophthalmology, 87: 834-838.

[12]. Zaidi, T., Mowrey-McKee, M. and Pier, G., 2004. Hypoxia increases corneal cell expression of CFTR leading to increased Pseudomonas aeruginosa binding, internalization, and initiation of inflammation. Invest Ophthalmol Vis. Sci., 45: $4066-4074$.

[13]. Verhelst, D., Koppen, C., Looveren, J., Meheus, A. and Tassignon, M., 2005. Clinical, epidemiological and cost aspects of contact lens related infectious keratitis in Belgium: results of a seven-year retrospective study. Bull. Soc. Belge. Ophtalmol., 297: 7-15.

[14]. Amos, C. and George, M., 2006. Clinical and laboratory testing of a silver-impregnated lens case. Cont Lens Anterior Eye, 29: 247255.

[15]. Das, S., Sheorey, H., Taylor, H. and Vajpayee, R., 2007. Association between cultures of contact lens and corneal scraping in contact lens-related microbial keratitis. Arch Ophthalmology, 125:1182-1185.

[16]. Yung, M., Boost, M., Cho, P. and Yap, M., 2007. Microbial contamination of contact lenses and lens care accessories of soft contact lens wearers (university students) in Hong Kong. Ophthalmic and Physiological Optics., 27: 11-21.

[17]. Kodjikian, L., Casoli-Bergeron, E., Malet, F., Janin-Manificat, H., Freney, J., Burillon, C., Colin, J. and Steghens, J., 2008. Bacterial adhesion to conventional hydrogel and new silicone hydrogel contact lens materials. Graefes. Arch Cline. Exp. Ophthalmology, 246: 267-273.

[18]. Behlau, I. and Gilmore, M., 2008. Microbial biofilms in ophthalmology and infectious disease. Arch Ophthalmology, 126: 15721581 .

[19]. Yoshifumi, I., Jyotsna, C., Pranab, K., Mukherjee, K., Ali, A., Loretta, B., Szczotka-Flynn, E., Jonathan, H., Kerry, O. and Mahmoud, A., 2008. Fusarium and Candida albicans Biofilms on Soft Contact Lenses:Model Development, Influence of Lens Type, and Susceptibility to Lens Care Solutions. American Society for Microbiology, 52: 171-182.

[20]. Dutot, M., Paillet, H., Chaumeil, C., Warnet, J. and Rat, P., 2009. Severe ocular infections with contact lens: role of multipurpose solutions. Eye (Lond)., 23: 470-476.

[21]. Szczotka-Flynn, L., Pearlman, E. and Ghannoum, M., 2010. Microbial contamination of contact lenses, lens care solutions, and their accessories: a literature review. Eye Contact Lens, 36: 116-129.

[22]. Fleiszig, S. and Evans, D., 2010. Pathogenesis of contact lens-associated microbial keratitis. Optom. Vis Sci., 87: $225-232$.

[23]. Hall, B. and Jones, L., 2010. Contact lens cases: the missing link in contact lens safety? Eye Contact Lens, 36: 101-105.

[24]. Nzeako, B. and Al-Sumri, S., 2011. The disinfecting potential of contact lens soutions used by Sultan Qaboos University students. Sultan Qaboos University Med. J.,11: 252-258.

[25]. Loretta, B., Szczotka-Flynn, O., Eric P. and Mahmoud G., 2012. Microbial Contamination of Contact Lenses, Lens Care Solutions, and Their Accessories: A Literature Review, PMC., October 28.

[26]. Joseph, P., 2013. 3; Ocular surface health with contact lens wear. Contact Lens and Anterior Eye, 36: S14-S21.

[27]. Philip, B., 2013. 4; Contemporary research in contact lens care. Contact Lens and Anterior Eye, 36: S22-S27.

[28]. Davey, G., Campbell, C. and Warnock, D., 1996. Mycological techniques J. Cline. Pathology, 49: 95-99.

[29]. Nester, E., Anderson, D., Evans, C. and Nester M., 2009. Microbiology: A human perspective. McGraw Hill. pp. $336-337$.

[30]. Pasricha, G., Savitri, S., Prashant, G., Ramesh, K. and Aggarwal, A., 2003. Use of 18S rRNA Gene-Based PCR Assay for Diagnosis of Acanthamoeba Keratitis in Non-Contact Lens Wearers in India. J. Cline. Micro., 41: 3206-3211.

[31]. Coulombier, D., Fagan, R., Hathcock, L. and Smith, C., 2001. Epi Info 6 Version 6.04. A Word Processing, Database and Statistical Program for Public Health. Centers for Disease Control and Prevention, Atlanta, Delaware, USA. 